\title{
a importância da viageem UMA CORRESPONDÊNCIA POÉTICA ENTRE POETAS E CARAÍBAS
}

\section{The importance of travel: a correspondence between poets and caraíbas}

\section{Leila Melo Coroa ${ }^{1}$ Mayara Ribeiro Guimarães ${ }^{2}$}

Resumo: Este trabalho se dispôs a interpretar as longas peregrinações realizadas pelos tupisguaranis de modo a estabelecer relação com uma noção de viagem que é muito cara à linguagem poética, aliás, própria do estatuto do poeta, ou seja, daquele que se lança no fazer poético; assim como a imagem ascética e errante do caraíba, enquanto designação também do poeta. Deste modo, pensar nesta correspondência entre o ritual indígena em busca de um território sagrado para refletir no próprio expediente poético, e em como ambos dialogam, ao entenderem, cada um à sua maneira, a importância da viagem, de sua trajetória e errância, mas também da figura do profeta e do poeta, ou seja, daqueles que se dispõem obstinada e religiosamente, no sentido da busca pelo sagrado, nesta perquirição. Para estabelecer tal correspondência, usaremos a trajetória poética de Max Martins, pois ele incorporou tais aspectos. Entre os teóricos que direcionaram este trabalho estão Maurice Blanchot, Martin Heidegger, Benedito Nunes, Edmond Jabès, entre outros.

Palavras-chave: Caraíba; Poeta; Max Martins; Viagem.

Abstract: This work was prepared to interpret the long pilgrimages made by the Tupi-Guarani in order to establish a relationship with a notion of travel that is very dear to the poetic language, in fact, proper to the status of the poet, that is, of the one who launches into poetic making; as well as the ascetic and wandering image of the caraíba, while also designation to the poet. Thus, thinking about this correspondence between the indigenous ritual in search of a sacred territory to reflect on the poetic expedient itself, and how they both dialogue, when they understand, each in their own way, the importance of the journey, it's trajectory and wandering, but also the figure of the prophet-poet, that is, one who is obstinately and religiously disposed, in the sense of the search for the sacred, in this investigation. To establish such correspondence, we will use Max Martins poetic trajectory, as he incorporated these aspects. Among the theorists who

1 Mestranda em Estudos Literários na Universidade Federal do Pará (UFPA). E-mail: leilacoroa@ gmail.com.

2 Doutora em Literatura Brasileira pela Universidade Federal do Rio de Janeiro (UFRJ). Professora de Literatura Brasileira na Universidade Federal do Pará, editora-chefe da Revista MOARA, revista do programa de pós-graduação em Letras da UFPA, atua também como professora no PPGL na área de Estudos Literários. E-mail: mayribeiro@uol.com.br. 
directed this work are Maurice Blanchot, Martin Heidegger, Benedito Nunes, Edmond Jabès, among others.

Keywords: Caraíba; Poet; Max Martins; Travel.

- Com que tu sonhas?

- Com a terra.

- Mas tu estás sobre a terra.

- Sonho com a terra onde estarei.

- Estamos um em face do outro e temos nossos pés sobre a terra.

- Conheço apenas as pedras do caminho que leva, dizem, à terra.

Edmond Jabès. O livro das questões.

Em Terra sem mal, Hèléne Clastres, apoiada nos registros dos cronistas do período da chegada ao Brasil dos europeus, realiza um estudo antropológico acerca das comunidades indígenas do Brasil colonial, especificamente das tribos tupis-guaranis. Clastres capitaliza sua pesquisa na busca dessas sociedades primitivas por um espaço que para elas representaria um lugar sem todo e qualquer extrato de sociedade, como já se configurava, mesmo para aqueles povos, e naquele tempo, de forma ordenada e política.

O texto de Clastres nos traz a dimensão do significado das longas peregrinações realizadas pelos tupis-guaranis em busca da Terra sem mal, bem como a insígnia dada a esses povos como seres sem qualquer tipo de religiosidade. Ressalta também a distinção entre os pajés e os caraíbas, a importância do discurso e da palavra, trata sobre as últimas gerações, e, claro, sobre as mudanças que se seguiram desde os tempos dos primeiros registros, até os tempos atuais.

Todavia, com este trabalho pretende-se explorar dois aspectos específicos acerca do texto de Clastres: as longas peregrinações e sua relação com uma noção de viagem que é muito cara à linguagem poética, aliás, própria do estatuto do poeta, ou seja, daquele que se lança no fazer poético; assim 
como a imagem ascética e errante do caraíba, enquanto designação também do poeta3.

Deste modo, partimos dessa correspondência entre o ritual indígena em busca de um território sagrado para pensar no próprio expediente poético, e em como ambos dialogam, ao entenderem, cada um à sua maneira, a importância da viagem, de sua trajetória - errância - mas também da figura do profeta-poeta, ou seja, daquele que se dispõe obstinada e religiosamente, no sentido da busca pelo sagrado, nesta perquirição. Para estabelecer tal correspondência, usarei a trajetória poética de Max Martins, ao entender que Max sempre buscou por esse desterro próprio daqueles que não pertencem à parte alguma, pois se lançaram há muito tempo numa jornada em busca de algo maior.

Sobre a figura do caraíba, ou caraí, Clastres nos explica ser distinta do pajé, haja vista existir sobre essas denominações determinada hierarquia fundamental para a ampla compreensão do funcionamento das atividades xamânicas. Assim, ao pajé cabe a função da cura, da prevenção e adivinhação dos nomes que receberão os recém-nascidos, ao passo que a categoria dos caraís denota ascensão, que corresponde à importância e ao prestígio das atividades realizadas por esses grandes xamãs.

A imagem dos caraís, para além da função de curandeiros, coloca-os, segundo Clastres, como grandes líderes religiosos, e em muitas ocasiões, políticos também. Eles representam o elo entre a comunidade e os grandes espíritos, os quais o caraí evoca, pois são mediadores entre esses dois mundos, e não à toa, representavam significativa preocupação, sobretudo aos missionários, uma vez que se colocavam como obstáculo para as intenções de cristianização operadas pelos jesuítas.

Clastres afirma ser unânime a atribuição aos caraís de grandes inimigos do intento missionário, sobretudo porque se conferia a essas figuras - e Clastres pontua que assim também era para os índios-um poder obscuro. Existia sobre esses xamãs determinada ambiguidade e obscuridade, uma impressionante capacidade comunicativa e, consequentemente, persuasiva, que apesar de

3 Este artigo orienta-se única e exclusivamente numa aproximação teórica e ensaística entre duas culturas, não tendo ocorrido nenhum tipo de experiência etnográfica acerca da correspondência que se pretendeu entre a figura do caraíba e a de Max Martins. Logo, o texto deve ser lido tão somente como uma proposta teórico-poética em torno dessas duas figuras. 
representar um claro empecilho à conversão dos indígenas, não deixava por sua vez de causar admiração pela forte influência exercida aos demais.

Um aspecto especial do modo de vida dos caraíbas, e que também expressava um comportamento que se diferia dos demais, diz respeito ao isolamento vivenciado por eles; pois eles experienciavam longos momentos de solidão, e, em muitas ocasiões, afastavam-se do grupo que estivessem por ora liderando, num movimento de insulamento profundo. Sobre este aspecto:

Mais ainda do que uma atitude apenas destinada a ressaltar sua importância, esse isolamento deliberado era uma maneira de marcar que eles possuíam um estatuto à parte, que, de fato, não pertenciam verdadeiramente a uma comunidade, que não eram de lugar algum. Com efeitos, eles não só viviam afastados numa morada feita para seu uso exclusivo, como ainda permaneciam pouco tempo na mesma aldeia. Deslocavam-se constantemente, percorrendo províncias inteiras. Todos os autores insistem na sua vida errante e Thevet, por exemplo, trata-os de "vagabundos". (CLASTRES, 1978, p. 41).

Ora, é sabido que ao longo da história muitos foram os escritores e poetas que receberam tais alcunhas: vagabundos iluminados, errantes, amaldiçoados são alguns dos adjetivos relacionados. Errância e viagem são duas imagens que andam sempre juntas, pois o sujeito peregrino, em constante deslocamento, ou seja, aquele que apreende a viagem para si, não pode ser outra coisa que um errante, de terra em terra e sem destino final. Sobre esta condição, Blanchot afirma:

O poeta está em exílio, está exilado das ocupações regulamentadas e das obrigações limitadas, do que é resultado, realidade apreensível, poder. (...) Esse exílio que é o poema faz do poeta o errante, o sempre desgarrado, aquele que é privado da presença firme e da morada verdadeira. (BLANCHOT, 2003, p. 259).

Blanchot compreende estar exilado para além do significado habitual que damos ao termo. Para o pensador francês, ele representa isolar-se, sugere a premência de um desarraigamento e da necessidade do poeta de pertencer à parte alguma, pelo menos não unicamente, haja vista que para este autor o estado de exílio a que se submetem os poetas é um estado imanente do ofício do poeta; o que significa dizer que todo poeta já carrega consigo 
esta condição, pois ela é a marca de uma indeterminação essencial para o surgimento de sua voz poética.

As figuras, tanto do caraí, quanto do poeta, pertencem a essa instância, pois ambas incorporam esses eventos em que urge a necessidade do isolamento, do exílio. Os grandes xamãs muitas vezes não apenas se afastavam da aldeia, como também evitavam misturarem-se com os demais, inclusive durante o tempo de permanência em determinada aldeia, e para eles eram construídas moradas isoladas dos demais habitantes. O movimento de comunhão junto aos demais se dava, além das caminhadas rumo à terra sagrada, nos momentos em que o caraí se dirigia à aldeia para proferir seu discurso.

Agora, para que este discurso se realizasse, eram necessárias, claro, reflexão, inspiração, iluminação, que apenas seriam possíveis mediante essa espécie de meditação que o isolamento promovia e auspiciava. Ali, junto à floresta, exilado de tudo e de todos, era o momento de evocar aos grandes espíritos à iluminação da palavra, da palavra sagrada que seria compartilhada depois com os demais.

Distante da floresta, mas também exilado, encontra-se o poeta. A sua linhagem pertence ao não lugar, ao exílio que se instaura e que proporciona a única morada possível: a poética. Por meio desta incursão que menos tem a ver com uma ideia territorial, mas sim com um movimento de imersão para dentro de si; será justamente neste momento que a viagem acontecerá, enquanto percurso do pensamento.

Com Max Martins, o sentimento de deslocamento e insulamento é algo que irá perpassar por quase toda a sua poesia, mas que talvez se evidencie com maior profusão nos livros Caminho de Marahu e Para ter onde ir, que não à toa indicam em seus títulos justamente essa atmosfera de transitoriedade e submersão. Para que se consiga penetrar nesta atmosfera - quase sempre rarefeita - é importante que se pense na significação do caminho para o poeta e em como ele se coloca enquanto viajante desta trajetória poética. Em Max, há o desejo de obter um sentido para a viagem, não importando para onde se vai, e sim atento ao caminho, ao percurso que irá se delinear, porque a busca é o que o move.

Ao pensarmos na concepção de transitoriedade presente na obra de Max, é importante que se reflita sobre as razões que impulsionaram o poeta a se colocar nesse estado de constante deslocamento. Para Max, o deslocamento 
vem ao encontro de uma sensação frequente de mutação, em que se deslocar sugere mudança, significa deixar algo para trás e incorporar outro novo. 0 sentido de mutação que perpassa, especialmente os poemas de Para ter onde ir, reforça a ideia de que nada deveria estar em situação estática, ao contrário, por estar em processo de transformação é que precisamente necessita deste fluxo contínuo; afinal, de mutação em mutação é que se alcança a terra sem mal, que para o poeta vem a ser o seu território sagrado: o poema.

Assim, como ponderou Davi Arrigucci Jr. no prefácio de Caminho de Marahu, essa busca constante pode se dar justamente no movimento de insulamento e expansão, aspecto marcante da poesia de Max, em que por momentos o poeta inclina-se para o seu interior da mesma forma que se dispõe para o novo, para aquilo que ainda não foi realizado. Fazendo alusão ao texto de Benedito Nunes, Max Martins, mestre aprendiz, é disso justamente do que se trata seu nomadismo, que irrompe também na sua escrita, em fases, em momentos de exploração do poeta sobre outras formas, outras possibilidades dentro do seu fazer poético (NUNES, 2009, p. 338).

Tais movimentos, tanto de expansão quanto de isolamento, marcam precisamente esse constante deslocar-se na trajetória poética de Max, pois apontam para um caminho desconhecido, e, por conta disso, errante, uma vez que ao lançar-se ao desconhecido, ao arriscar-se por vias inexploradas, o poeta reafirma não apenas certo obscurantismo dentro de sua poesia, como também faz luzir a sua natureza exilada; de um exílio que se dá por meio de um constante fluxo, de nunca aportar-se definitivamente em nenhuma margem, de nunca pertencer a algo unicamente; de um ir e vir que faz desse movimento a força propulsora para a construção da sua voz, justamente porque se sobrepõe às margens, porque já não pertence mais somente a elas, ainda que precise retornar eventualmente. Estar exilado nesse sentido é estar sempre se deslocando, num ir e vir sem fim; e nesta inquietação fazer surgir as mutações. Desse modo, a ideia de trânsito está totalmente arraigada à de exílio.

Em Para ter onde ir, o poema que inaugura o livro também traz consigo toda a força do significado de trânsito, em que apenas caminhando é que se obtém sentido, num movimento que revela mutação, num ir e vir que transcorre tal como o rio: 


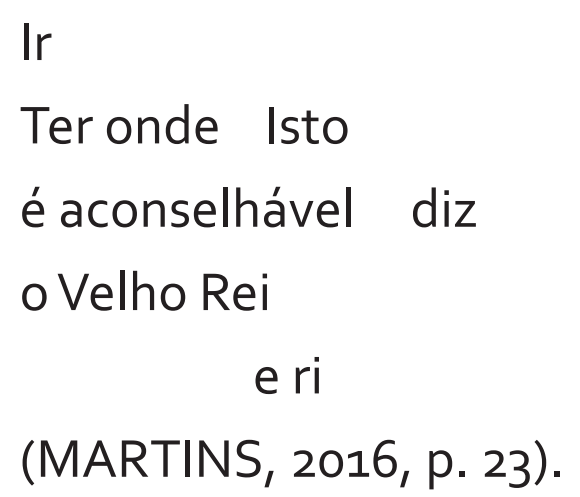

"Ir" aponta para a necessidade de sair de um lugar a outro, de deixar algo e agregar o novo, o ainda não explorado; incorporando, assim, o sentido de viagem. Esse desejo por partir, novamente, tem menos a ver com um objetivo e mais com o caminho, e assim como em Ítaca, de Kaváfis, o importante não é chegar em um lugar - neste caso a Ítaca - mas sim a própria caminhada. O poeta, peregrino da sua própria viagem, inaugura um novo sentido para a peregrinação ao se compreender enquanto objeto de mutação, pois faz da sua partida, do seu ir, a busca por um caminho, uma vez que faz de si próprio o objeto de partida e retorno.

O sentimento de não pertencimento e a necessidade de afastamento são aspectos que convergem na experiência poética de Max Martins, poetaprofeta, dedicado e resignado ao seu ofício-mor. É sabido do esmero com o qual Max encarava o fazer poético, o devir-escritor, e o que isto custa àqueles que se lançam nessa empreitada, mas também corresponde e dialoga com a dimensão da figura do profeta indígena, que mantém os mesmos cuidados e práticas para a organização do seu discurso, do canto que irá entoar e que será o canal de aproximação e convencimento para a aldeia. Se para Max o não pertencer, o ser estrangeiro, nômade, são sentimentos imanentes, assim também o era para o xamã:

[...] estar fora da comunidade não significa apenas morar afastado, ou melhor, esse próprio afastamento só comparece para manifestar uma exterioridade mais profunda: a que situa o profeta fora, do ponto de vista social (e não apenas espacial), do que precisamente constitui uma comunidade: da rede de parentesco. (CLASTRES, 1978, p. 41). 
A figura do caraí se revela imprecisa no que diz respeito a sua origem, sua morada verdadeira, isto porque seu ir e vir lança sobre si esta indeterminação. Clastres nos dirá em seu texto que a condição marginalizada do caraí, ou seja, esta indeterminação que constituía seu aspecto errante, é fundamental para que se consiga apreender este profeta na sua diferença.

Sua figura era responsável por conduzir os índios da aldeia rumo à busca desta terra sagrada, abundante em todos os sentidos, representante na terra daquilo que nós, cristãos ocidentais, acreditamos poder alcançar somente no além-morte. Esta ideia de que a Terra sem mal viria a ser o único lugar onde estariam a salvo do dilúvio, da catástrofe anunciada e aguardada, também corresponde às nossas crenças ocidentais. Logo, a ascensão a este território não poderia vir sem esforço, e era justamente em torno da promessa deste espaço sagrado que gravitava toda a noção de religiosidade dos tupis-guaranis, oriunda deste xamanismo que fez luzir sobre os demais indígenas a posição do caraí, mas que também denotava este movimento de merecimento, e de que não haveria espaço para aqueles que não se dispusessem a percorrer os caminhos que levariam à Terra sem mal.

Um aspecto crucial da busca por este espaço sagrado, reservado aos mais bravios e dispostos, trata de seu aspecto incessante, do movimento de deslocamento contínuo e de uma viagem que tinha por essência ser interminável, e que, como pontua Clastres, apenas findou pela falta de migrantes.

Mas antes, muitos foram aqueles que genuinamente se lançaram à procura da Terra sem mal, nesta empreitada que, sobretudo, representava uma longa e dura ascese, com muitos momentos de fome floresta adentro, submetidos a incansáveis rituais de dança, e que mesmo em condições adversas, e ainda que com o fracasso de muitas expedições, nunca deixaram de perseverar pelo seu propósito. Todavia, se como afirma Clastres, a busca pela Terra sem mal já estava precipitadamente fadada a fracasso no próprio projeto que a sustentava, por qual razão empreendiam os tupis-guaranis nesta aventura?

Novamente, a imagem da viagem se inflama. A viagem para os tupisguaranis, esta longa e penosa travessia, cuja a possibilidade de proximidade se afastava a cada movimento em sua direção; era, assim como era para Max, mais valiosa que a chegada em si, pois que nesse percurso que se delineava 
é que brotavam as verdadeiras ambições desse projeto, ou seu verdadeiro sentido:

Pois suas longas peregrinações através do espaço representavam também o tempo necessário para se consumar a lenta mutação dos espíritos e dos corpos, sendo apenas ela capaz de torná-los dignos de ascender ao término da sua busca. E essa mutação pelo abandono das normas sociais. Eis aí a prova e o sentido da viagem: abandonar uma aldeia e um território é, simultaneamente, renunciar ao essencial das atividades econômicas, sociais e políticas que se enlaçam nesse espaço. (CLASTRES, 1978, p. 67).

Desse modo, a viagem, este espaço não territorial, e como indica Clastres, destinado unicamente a ser percorrido, é que instaura a mutação, o processo originado pela peregrinação que desembocará na busca, acima de tudo, da possibilidade deste devir, da sua preparação e transformação. O momento da migração, percebe-se tal qual o do poeta: não se trata ainda da grande chegada ao destino sonhado, mas do momento de espera e preparação. Trata-se de um instante em que ocorre o resguardo e o cultivo, e assim, movendo-se entre esses espaços é que, tanto o poeta quanto o caraíba, assumem seu destino de errância, aceitam este exílio na medida em que ele se configura: como um abrigo, para neste percurso, através da distância que se instaura, no seu autêntico reconhecimento e vivência, aproximar-se daquilo que mesmo ausente e longínquo se faz presente: o sagrado. Por isso seu vagar jamais será em vão ou arbitrário, pois ele alimenta e auspicia a ideia, a preparação, e isto, por si só, já valeria a empreitada.

Sobre isto, Blanchot denomina de apelo desejante, experiência do infinito da espera:

Euesperava. Espera sem fim, existência reduzidaà estéril expectativa sem presente, que no entanto é também espera rica, plena do pressentimento no qual se prepara a vinda e a visão daquilo que sempre vem: Eu esperava e vi chegar. O que é visto? A vinda. Mas o que vem? Isto permanece indeterminado, ou melhor, é dito no neutro, embora, neste indeterminado e nesse neutro, esteja certamente compreendida a aproximação do "agora" no qual o dia amanhece, mas que não poderia ser visto diretamente, que é visto apenas enquanto vinda, sendo o dispensador de tudo aquilo que pode advir. (BLANCHOT, 2001, p. 81). 
Podemos dizer que neste aguardar é que se fundam as questões poéticas ou de cunho profético, haja vista que o sagrado está em toda parte, sobretudo na manifestação das questões. Instalação poética que brota mesmo da errância, do vaguear peregrino, alheio a fronteiras, sem morada segura ou definitiva. É justamente neste espaço de tempo, na construção dessa distância e na experiência do não lugar, que o sagrado, ou a manutenção da sua promessa, tão importante quanto, acontecem.

Para Heidegger, o homem é lançado ao abismo, sem fundamento, ou seja, a sua essência, enquanto transcendência se situa nessas condições mesmas, e diante dessas experiências e possibilidades é que o homem se caracteriza como "[...] um ser ao longe", ou seja, um ser da distância. Portanto, apenas "por meio de distâncias que, em sua transcendência, ele forja para si e em relação ao todo ente, e assim começa a operar dentro dele a verdadeira proximidade para com as coisas" (HEIDEGGER, 2008, p. 188).

O incessante deslocamento promovido pelas experiências de viagem delineará um percurso que é fundamentalmente o percurso do pensamento. "O caminho é um caminho do pensamento" (HEIDEGGER, 2001, p. 11), possibilitando ao poeta, mas também ao caraí, vaguear peregrino, no desterro próprio do seu ser. Eles seguem pelo mundo nômades e sem lugar, rumo à construção de sua existência.

A viagem que se instaura caminha junto à promessa, e assim, uma autentica a outra, elas se sobrepõem na consciência dessas duas figuras, pois dão à coisa seu ritmo, ideia de impossibilidade em que se costura a urgência de um desarraigamento profundo:

[...] para preservar a possibilidade desse desejo impossível, escolhe-se o risco de perder todas as certezas: a das experiências sedentárias, como as das verdades estabelecidas. Se o pensamento dos tupis-guaranis é profético, é por pressentir a salvação como inacessivel e por saber que, para continuar acreditando nela apesar de tudo, é preciso constantemente ultrapassar todos os limites, quer dizer, renunciar a toda forma de enraizamento. (CLASTRES, 1978, p. 112).

O projeto indígena diz respeito a um profundo abandono das atividades econômicas e políticas tradicionais, mas também da renúncia por todo e qualquer tipo de proibição, de tolhimento. Podemos encarar isto como um 
processo de dissolução de uma identidade que fora construída e que não corresponde mais às expectativas futuras, logo, é necessário bani-la, cessar com esta estrutura em prol do surgimento de algo novo. Novamente aqui chegamos a uma feliz correspondência: Max, ao incorporar a viagem e a errância provenientes dessa jornada, não pode mais ser fixado em um ponto específico, haja vista que seu incessante deslocamento não o permite. Este estado de não pertencimento promove a dissolução da identidade, que evoca em Max a imagem do rio e do apagamento de suas margens; essenciais para o aparecimento de sua voz poética, pois novamente, na poesia de Max, o poeta está sempre junto ao fluxo do rio, onde ninguém habita, somente nômades.

A ideia de dissolução de uma identidade e de errância exprimem os sentimentos de dúvida que apontam para isto: estar perdido, por não saber mais, por ter se perdido junto ao fluxo do rio, e que apesar de fazer parte dele, já não consegue mais se encontrar ali, tornando-se estremecido, estranhado. Esta situação provoca no autor um abismo existencial e sua condição errática inviabiliza a possibilidade de uma margem específica onde seja possível atracar, por essa razão mesma é que o caminho se faz infindo, reforçando a necessidade de transformação, de mutação que irá garantir sua sobrevida, e consequentemente, a do poema:

Meu nome é um rio

Meu nome é um rio que perdeu seu nome

Um rio

nem sim

nem não

Nenhum

Somenos correnteza

Água masturbada em vaus

em po

luído orgasmo entre varizes

sêmem sem mim

Mesmice

Onde está meu nome Lá neste rio de lama sem minha memória

[e rumo?

Neste amarfanhado leito de inchada falha?

Meu nome é um rio cotoco --- um Ícone 
De barro

Barroco

Um rio que só se-diz

\section{Seduz-se}

Se afaga e afoga

em ego e água: Aquário

Meu nome é um rio tapado

$$
\text { (poço) }
$$

E aqui se aquebrantou meu nome

sua viagem e osso

É esta a sua fissura? E o seu rosto é este

\section{Escuro}

atrás da porta

$$
\text { espelho }
$$

exposto à febre

$$
\text { à fera de si mesmo? }
$$

\section{Ensimesmado}

meu nome é um rio que não tem cura

(MARTINS, 2016, p.35).

Dentro do universo do poema, o rio para Max perde toda esta tradicional simbologia, pois subtrai-se dessa imagem desgastada justamente aquilo que ela já cristalizou em narrativa. Trabalho desconstrutor de rasura deste rio que marcará essencialmente uma diferença, recolocando também os elementos num tempo-espaço que será apenas um fora de tempo por onde se moverá a escritura, como no poema acima "Rasuras" de O risco subscrito.

Este rio perde toda a sua identidade e verossimilhança, pois dá conta da perda de um eu, de um processo de estilhaçamento em que se instaura a dificuldade para nomear. Uma identidade que se mistura com a do rio, logo a impossibilidade para dar nome também a esse rio. Tanto "meu nome" quanto "um rio que perdeu seu nome" apontam para o processo de deslocamento e transformação, e por estarem nestas circunstâncias não estão passíveis de atribuição, uma vez que o processo é de mutação. 0 caminho, assim como confirma Max em outro poema intitulado "A asa e a serpente", é um caminho em que o poeta escreve e descreve, dissolvendose [...] (MARTINS, 2016, p. 49). 
A diferença sobrevém também por um movimento antropofágico, de contrabando de pensamentos múltiplos, do zen-budismo, mas também de outras formas plásticas, colagens não só de imagens - dos diários que Max mantinha - bem como de outros textos e da arte como um todo. Ondulações entre as escritas que vão se colando umas nas outras, incorporando-se nesse processo rizomático que expande as suas conexões e que nunca se fecha sobre si, está sempre aberto à experimentação e sempre se deixando atravessar por outras linhas de intensidade que o atravessam. O que confere multiplicidade, no sentido deleuziano mesmo, de intensidade e potência que a palavra pode adquirir. Deleuze e Guattari explicam o rizoma:

Um rizoma não começa nem conclui, ele se encontra sempre no meio, entre coisas, inter-ser, intermezzo. A árvore é filiação, mas o rizoma é aliança, unicamente aliança. A árvore impõe o verbo "ser", mas o rizoma tem como tecido a conjunção "e... e ... e ...". Há nesta conjunção força suficiente para sacudir e desenraizar o verbo ser. Para onde você vai? De onde você vem? Aonde quer chegar? São questões inúteis. (DELEUZE e GUATTARI, 2011, p. 48).

A força dessa conjunção consiste precisamente naquilo que caracteriza a viagem, seu aspecto processual, desterritorializante, que se expande sempre estabelecendo conexões com o que encontra pelo caminho; mas também por afirmar que a chegada não importa, tampouco a partida, o que reafirma o status estrangeiro, uma vez que origem e destino perdem importância para a jornada. Ideia também de soma e mutação, afinal a jornada simboliza também transformação, essencial na poesia de Max.

Ao proferir seu discurso, ao se lançar no terreno da palavra sagrada proferida e compartilhada, o profeta indígena também se investe de todo o erro que representa a experiência em busca da Terra sem mal, de todo processo de apagamento do que fica para trás e da promessa inalcançável que o futuro aspira:

Ouça-se a palavra profética: e rompem-se os quadros que garantem as existências, todo o espaço medido e diferenciado do social. É o error que, arrebentando as coordenadas espaciais e temporais que as subordinavam umas às outras, isola as vidas e as justapõe. Todos de repente são profetas e isso deixa de ser um estatuto. $\mathrm{Na}$ extensão sem limite e sem diferença da floresta indefinidamente atravessada, 
só é possível habitar, mas não residir; subsistir, mas sem produzir, largam-se mortos, sem fundar linhagem. Um puro deslocamento, que não implica volta alguma para trás nem acabamento algum. Impossível é estabelecer novos territórios em outro lugar, garantir novas leis - porque a salvação está sempre adiante, sempre fora do limite: perdida, mal entrevista. Por ser sem limite, o espaço torna-se, no mesmo movimento, sem saída. (CLASTRES, 1978. p. 115).

Trata-se de uma busca que também rui com uma noção de identidade, afinal, o projeto se situa na destruição da ordem vigente, da estrutura que ramifica o modo de vida destes índios. O processo de viagem também será incessante, e a possibilidade de eles se fixarem em um ponto específico também, pois a promessa de novas leis, de uma nova forma de ser, depende desses movimentos de mutação que apenas a longa e ascética jornada floresta adentro pode salvaguardar.

Assim, podemos depreender a importância desta jornada para ambos, e em como o processo é aquilo que mais valida a experiência: é o que garante sua forma e seu fundamento, mas também podemos observar como ele é, no final das contas, a própria experiência. O caraí e o poeta se encontram nesta parte do caminho: para além dos limites de toda e qualquer fronteira, errantes e em busca da promessa da palavra sagrada.

\section{consideracões finais}

Este trabalho nasceu do constante interesse por tudo o que circunda, motiva e representa o devir-poético, sobretudo do autor escolhido, Max Martins, poeta paraense, tão pouco conhecido do grande público leitor do país, infelizmente. Trazer à tona este nome, assim como um pouco da sua experiência poética e a maneira como ele a encarava é fonte de satisfação profunda. Além disso, poder ressuscitar este importante texto - Terra sem mal -, de Hèlene Clastres, sobre as longas peregrinações realizadas pelas comunidadestupis-guaranis, bem como aquilo que as motivava, é igualmente satisfatório.

Assim partimos destes dois polos aparentemente distantes, tanto culturalmente quanto temporalmente para uni-los em um propósito, percebendo uma bonita e profunda correspondência entre ambos: esta 
noção de viagem que atravessa suas estórias e que nos faz refletir a respeito de ambos.

Para Max Martins a viagem será parte constituinte de seu expediente poético, isso porque ele apreendeu a jornada enquanto possibilidade de não pertencer à parte alguma, de aprofundar-se no processo e deste movimento fazer despontar sobre sua escrita amplas possibilidades, distintas; o que corresponde a um movimento de mutação que é possível apenas àqueles que se lançam à migração. Mas também dá conta de um nomadismo que se instaura dentro da própria base material de seus textos, e isto é imprescindível para Max, pois este poeta sempre esteve inclinado e aberto para o novo, para novas explorações; e assim como escreveu Benedito Nunes, por conta disso, sua escrita se deu em saltos, ou seja, sempre em busca de outras formas de linguagem.

Para a figura do caraí esta viagem ascética e obstinada também se estrutura sobre uma forte necessidade de vivenciar o processo que vai se delineando floresta adentro, pois sobre a figura do caraí também recai a insígnia da imprecisão acerca de sua origem, situando-a neste nível de imprecisão que dá conta de sua errância e que serve para apontar que o percurso era aquilo que mais importava, não sua origem ou chegada.

Ambos costuraram suas motivações sobre esta indeterminação e imprecisão que corresponde à viagem, ao vaguear peregrino alheio a fronteiras ou regras fixas. Situando-se sempre à margem, errantes e sem origem em busca do sagrado, e em como para cada um, ao seu modo, isto significava.

\section{referências}

BLANCHOT, Maurice. O espaço literário. Rio de Janeiro: Rocco, 2011. A conversa infinita 1. São Paulo: Escuta, 2001.

CLASTRES, Hèlene. Terra sem mal. São Paulo: Brasiliense, 1993.

DELEUZE, Gilles; GUATTARI, Félix. Mil Platôs vol. 1. Rio de Janeiro: Editora 34, 2011.

HEIDEGGER, Martin. "A essência do fundamento". In: Marcas do caminho. Trad. Márcia de Sá Cavalcante Schuback. Petrópolis: Vozes, 2008. 
. Ensaios e conferências. Trad. Emmanuel Carneiro Leão, Gilvam Fogel e Márcia de Sá Cavalcante Schuback. Petrópolis: Vozes, 2001.

MARTINS, Max. Para ter onde ir. Organização \& notas Age de Carvalho; prefácio Maria Esther Maciel. Belém: Ed. Ufpa, 2016.

O risco subscrito. Belém: Ed. Ufpa, 2016.

NUNES, Benedito. "Max Martins, mestre aprendiz". In:

A clave do poético. Organização e apresentação Victor Sales Pinheiro. São Paulo: Martins Fontes, 2009.

Artigo recebido em: 02/02/2020 Aceito em: 24/06/2020 